\title{
ERRATUM
}

\section{Vector species richness increases haemorrhagic disease prevalence through functional diversity modulating the duration of seasonal transmission - ERRATUM}

\author{
ANDREW W. PARK, CHRISTOPHER A. CLEVELAND, TAD A. DALLAS and \\ JOSEPH L. CORN \\ doi:10.1017/S0031182015000578, Published by Cambridge University Press, 24 July 2015
}

The publisher apologises for the link to the Supplementary Material being incorrect. On page 878, the Supplementary Material section should read as follows:

SUPPLEMENTARY MATERIAL

To view supplementary material for this article, please visit https://doi.org/10.1017/S0031182015000578

REFERENCE

Park, A. W., Cleveland, C. A., Dallas, T. A. and Corn, J. L. (2015). Vector species richness increases haemorrhagic disease prevalence through functional diversity modulating the duration of seasonal transmission. Parasitology 143, 874-879. 